\title{
Stomatocystis goerresi, a new species of gregarine parasite (Apicomplexa, Monocystidae) from the invasive Japanese earthworm Amynthas tokioensis (Megascolecidae), with a description of the parasite's life cycle
}

\author{
Joseph J. Schall iD
}

Department of Biology, University of Vermont, Burlington, Vermont, USA

\begin{abstract}
Stomatocystis goerresi sp. n., a gregarine (phylum Apicomplexa, Monocystidae) parasite of an important invasive earthworm in North America, Amynthas tokioensis (Beddard), is described. This is the second species placed into the genus, and details of its morphology and life cycle support Stomatocystis Bandyopadhyay, Mitra et Göçmen, 2006 as a valid taxon. The new species is described using standard nomenclature, measurements, shape descriptors, and photographs of living cells. The parasite was found only in A. tokioensis, and absent in sympatric earthworm species, suggesting it arrived when the earthworms were introduced from their origin from Japan. The species is distinctive from the type species in the genus, S. indica Bandyopadhyay, Mitra et Göçmen, 2006, in being substantially larger in all stages, found in only the host's seminal vesicles, and found in a different host species from East Asia. The distinctive trophozoites/gamonts develop a large funnel structure ringed with a collar of pronounced ridges, and the funnel appears even in the smallest cells. This funnel varies greatly in relative size (to the cell body) and shape, sometimes forming a large fan. The life cycle of $S$. goerresi is described including distinctive syzygy in which the funnels fuse and then produce a large cell with local centres of isogamete production (thus sex without gender). Gametes are large ( $\sim 5 \mu \mathrm{m})$ spheres with complex tips. Oocyst production is large, $>1,000$ per mature gametocyst. The genus Stomatocystis is placed into the Monocystidae, but the life cycle of the new species differs from those of other monocystid taxa, which may mean the Monocystidae are not monophyletic or life cycles are variable within the family. Prevalence of $S$. goerresi at the type locality was high $(\sim 90 \%)$. The parasites destroy the earthworm's organ of sperm self-storage thus eliminating the male function in the hermaphroditic host which may influence the ability of the earthworm to invade and be successful at new sites
\end{abstract}

Key words: protist, standardised diagnostic morphology, introduced species, host specificity

The Apicomplexa are a diverse phylum of protist parasites, including important pathogens of humans such as the haemosporidian malaria parasites and the coccidian Toxoplasma gondii (Nicolle et Manceaux, 1908). The largest clade in the phylum, the gregarines, are parasites that exploit a very broad range of non-vertebrate hosts from terrestrial, freshwater and marine environments (Levine 1988, Desportes and Schrével 2013). Hosts include insects, other terrestrial arthropods, annelids in both fresh water and terrestrial environments, and marine mollusks, shrimp, and echinoderms. Approximately 1,800 gregarine species have been described (Votýpka 2016), but the true diversity is likely to be vast. For example, every species of insect appears to host one or more host-specific gregarines. Also, surveys of environmental DNA from tropical rainforest soils found that the gregarines represent the dominant protist diversity (Mahé et al. 2017, Lentendu et al. 2018). Rueckert et al. (2019) conclude from these patterns that there must be millions of species of gregarines yet to be diagnosed. Although the task for taxonomists who seek to reveal the diversity of likely gregarine species is daunting, perhaps even impossible, a broad goal should be to use new species descriptions to aid in an understanding of the host range and diversity of life cycles which would allow insights into the evolution and ecology of this important parasite group (Rueckert et al. 2019).

The basic life cycle of gregarines has been known for $>150$ years (von Stein 1848), and includes an extracellular feeding stage (trophozoites) that develops into a mating form (gamonts), mating of two gamonts (syzygy), development of gametes and then zygotes, and finally production of the durable environmental transmission stage (oocysts). Most known species seem to lack asexual replication (merogony) prior to the sexual stage; merogony is present in the other apicomplexan clades such as the malaria parasites. That stated, the complete life cycle is known for only a very small proportion of known gregarine species. The great host and habitat diversity of gregarines must be mir- 
rored by diversity of life cycles. Especially intriguing are the transmission adaptations in difficult environments. For example, minute pelagic tunicates of the genus Salpa Forskål host several known gregarine species; how the transmission stage moves from host to host in the open ocean is enigmatic (Desportes and Schrével 2013). Even familiar habitats and hosts, such as earthworms in soils, present intriguing questions in how the oocysts are distributed to allow infection of each generation of the worms.

With these issues in mind, I describe here a new gregarine species of Stomatocystis Bandyopadhyay, Mitra et Göçmen, 2006 (Monocystidae) that infects an important invasive Japanese earthworm in North America, Amynthas tokioensis (Beddard) (Megascolecidae). This earthworm was first recorded in New Jersey in 1953 and in Connecticut in 1955 (Reynolds 2018), but has become a significant pest, with disruption of forest soils throughout continental United States, only within the past decade (Nouri-Aiin and Görres 2019). The new gregarine species is only the second known in the genus Stomatocystis; the type species was described also from an species of Amynthas Kinberg, A. diffringens (Baird), but from India (Bandyopadhyay et al. 2006). Amynthas tokioensis in North America originated from Japan (Keller et al. 2017, Nouri-Aiin et al. 2021), so the genus Stomatocystis is thus extended to East Asia.

Here I present the complete life cycle of the parasite including trophozoites/gamonts (there is no clear distinction in the morphology of these two stages, unusual for gregarines), syzygy (mating between two gamonts), gametes, zygotes, and finally production of oocysts that pack into a spherical gametocyst. Oocyst counts show their production per gametocyst is large compared to other known monocystid gregarines. The morphology and life cycle of the new species have some novel features, perhaps even bizarre, that indicate the validity of the genus erected by Bandyopadhyay et al. (2006). For example, the genus name Stomatocystis ("mouth cell") refers to a structure termed crater-like by Bandyopadhyay et al. (2006), but for the new species it seems more funnel-like that is highly variable in form and can expand into a fan that is larger than the cell body. This elaborate structure is unique in the known gregarines. Also, the very large gametes are produced in patches within the fused gamonts, rather than around the periphery of the gamonts as seen in other monocystids.

I follow a protocol for species descriptions for the monocystids given by Keller and Schall (2020) that uses a terminology for life stages of Levine (1971), the set of morphological shapes assembled by Clopton (2004), large sample of measurements of living cells of all stages, and photographs of living cells. Braun and Lühe (1910) first noted that monocystid protists are often morphologically plastic, and the great variation in the funnel mouth of the new species required photographs and measurements of living cells. Keller and Schall (2020) also note that the host range of a new gregarine species should be exam- ined, especially for a parasite of an introduced host which could acquire a parasite from co-occurring earthworm hosts. Therefore, I examined sympatric earthworm species to demonstrate that the new species is host-specific for A. tokioensis. Gregarines are assumed to be primarily specific to host species, but host specificity has not been well studied (Clopton 2009).

\section{MATERIALS AND METHODS}

Amynthas tokioensis earthworms were collected from the litter layer and upper $5 \mathrm{~cm}$ of soils from July to October 2019, and identified using the morphological key of Chang et al. (2016) and a molecular barcode developed by Nouri-Aiin et al. (2021). After killing the earthworms in 50\% ethanol, they were washed in $\mathrm{dH}_{2} \mathrm{O}$, and then dissected. The parasites were found only in the seminal vesicles, the organ for storage of self-sperm for earthworms. The parasites typically packed the seminal vesicles, so they were removed by disrupting the tissue in earthworm Ringer's solution, and placed onto a microscope slide with $5 \mu \mathrm{l}$ of the solution that kept the large parasite cells from being crushed with application of a coverslip. Also, some preparations were made in a counting chamber (Neubauer) that allowed the parasites to float freely. To count the number of oocysts per gametocyst, gametocysts $(n=2)$ were removed to a drop of hand sanitiser which was viscous, and the gametocyst was smashed under a cover slip and inspected under the microscope. Photographs were made of every microscopic field that contained any oocysts ( $n=22$ and 29 fields for the two samples) and the oocysts then counted from the photographs. The parasite cells when stained for permanent archiving as museum specimens were often distorted with loss of detail; therefore, measurements and photographs here are made from living cells. Also, the parasites were observed to change their shape, especially the funnel structure. All measurements and photographs were made with the Moticam 1000 1.3MP Live Resolution camera for the light microscope and the Motic Image Plus 2.0.11 computer program (Motic, Richmond, British Columbia).

Twenty host earthworms were collected at one site, the University of Vermont Horticultural Research Farm, and all parasite stages were measured using the guidelines of Clopton (2004) and photographed. Earthworms were also collected from five other sites, all within Chittenden County, Vermont, to search for the parasite. Because A. tokioensis earthworms are often found in sympatry with local earthworms, the parasites infecting the seminal vesicles of eight sympatric earthworm species were examined. All earthworm samples were collected within Chittenden County, Vermont and the dissection and live preparation of slides of the seminal vesicle infections was done as above. The following local earthworm species were sampled and examined for the presence of the new species: Aporrectodea caliginosa (Savigny) $(\mathrm{n}=3)$, Amynthas hilgendorfi (Michaelsen) $(\mathrm{n}=15)$, Amynthas agrestis (Goto et Hatai) $(\mathrm{n}=635)$, Lumbricus terrestris Linnaeus $(\mathrm{n}=5)$, L. festivus (Savigny) $(\mathrm{n}=1)$, L. rubellus Hoffmeister ( $\mathrm{n}$ =3), Octolasion cyaneum (Savigny) $(\mathrm{n}=5)$, and Dendrobaena octaedra (Savigny) $(\mathrm{n}=1)$. 


\section{RESULTS}

Phylum Apicomplexa Levine, 1988

\author{
Class Gregarinomorphea Grassé, 1953, emended by \\ Cavalier-Smith (2014)
}

\section{Order Eugregarinorida Léger, 1900, emended by Adl et al. (2019)}

Family Monocystidae Bütschli, 1882

Subfamily Stomatophorinae Grassé, 1965
(syn. Stomatophoridae Bhatia, 1930)

Genus Stomatocystis Bandyopadhyay, Mitra et Göçmen, 2006

Stomatocystis goerresi sp. n.

Figs. 1, 2

ZooBank number for species:

urn:1sid:zoobank.org:act:A8679C49-775C-4A7E-A1B1-5B58DDFA8306

Description (based on parasites from 20 Amynthas tokioensis earthworm hosts examined from type locality, with live wet mounts of seminal vesicles under cover slip with parasite life stages defined by Levine (1971), and cell shapes from Clopton (2004 - Table 1, 2 and table matrix key). Funnel-shaped structure present at anterior end of gamont, and hence 'funnel'. All measurements are $\mu \mathrm{m}$ as range (mean and for $\mathrm{n}>30, \pm$ SD).

Early trophozoites orbicular (Clopton T1-x3) $(n=5)$ diameter 18-39 (29). Cell funnel appears on trophozoites as small as $17 \mu \mathrm{m}$ long, thus no clear morphological distinction between trophozoites and gamonts. Trophozoite/gamonts $(\mathrm{n}=120)$ cell body elliptoid (Clopton T1-C3) and funnel protruding of highly variable form, but when most reduced a flattened elliptoid (Clopton T1-F3), total length of vertical axis of symmetry $51-598(188 \pm 82)$, and cell body width, along horizontal axis of symmetry 42-354 $(103 \pm 50)$. Funnel rimmed by collar with parallel ridges $7-12 \mu \mathrm{m}$ long, separated by $2-4 \mu \mathrm{m}$, with variation depending on funnel distention Orbicular (Clopton T1-x3) vesicular nuclei $(\mathrm{n}=14)$ situated typically in centre of trophozoite/gamont cell body with diameter 16-38 (30).

Trophozoite/gamonts solitary until syzygy when funnels join $(\mathrm{n}=14)$ total length $265-552$ (432), then the two cells fuse as two deltoids (Clopton T2-E9) attached by the broad axis $(\mathrm{n}=13)$, length 186-417 (288), width 103-337 (221). Fused cells produce an orbicular gametocyst (Clopton T1-x3) containing two elliptoid (Clopton T1-D3) cells, and then produce an orbicular gametocyst (Clopton T1-E3) with one to several regions where gametes are produced $(n=10) 263-458(381)$. No sexual dimorphism in gametes (isogametes, thus lack of anisogamy). Gametes orbicular (Clopton T1-x3) $(n=11)$ 4-6.6 (5.1), with distinctive caps of tiny dot-like structures. Immature gametocysts with early-stage oocysts orbicular (Clopton T1-x3), ( $\mathrm{N}=49)$ 201-458 (325 \pm 60$)$. Mature gametocyts containing mature oocysts orbicular in shape (Clopton T1-x3) measured floating, $(\mathrm{n}=14)$ 197-232 (217). Oocysts fusiform, with extended terminal ends (Clopton T1-C4) $(\mathrm{n}=51)$ length $12-15(14 \pm 0.87)$, width 5-7 (5 \pm 0.64$).$ Number of oocysts for two gametocysts 1,834 and 1,984 .

Type and only known host: Amynthas tokioensis (Beddard) (Megascolecidae).

Type loc a lity: University of Vermont Horticultural and Research Farm, South Burlington, Vermont, U.S.A (44.4314N, $73.1992 \mathrm{~W}$ ), a mixed maple forest. The parasite was not detected in any A. tokioensis earthworms collected at the other sampled locations: Green Mountain Audubon Center, Huntington, Vermont (44.3467N, 72.9962W); Centennial Woods, Burlington, Vermont $(44.4757 \mathrm{~N}, 73.1870 \mathrm{~W})$; Colchester Garden (44.5394N, 73.1616W); Shelburne (44.3913N, 73.2116W); Colchester Town Hall (44.5313N, 73.2066W). All sites were within $\sim 30 \mathrm{~km}$.

Site of infection: Infections are found in seminal vesicles of A. tokioensis, typically filling and destroying the organ.

Prevalence of infection: Overall prevalence in A. tokioensis at the type locality was 174 of 195 (89\%; Clopper-Pearson 95\% Confidence Interval $84-93 \%$ ) by mid-summer, August, to time of seasonal host death in November.

Specimens deposited: Giemsa stained and cover-slipped. Holotype (USNM 1640943) and paratype (USNM 1640944) deposited at the Smithsonian Museum of Natural History (Washington, USA), and additional paratypes (HFTS5 and HFTS7) deposited at University of Vermont Zadock Thompson Zoological Collections, University of Vermont Natural History Museum, Burlington USA.

Etymology: Species epithet for the distinguished German soil scientist who has studied the invasive Amynthas earthworms for many years, Josef Görres.

Remarks. Stomatocystis goerresi is the second species identified in the genus; both species of Stomatocystis exploit Amynthas earthworms as their hosts. I place the new species into the genus Stomatocystis because of its production of a funnel-shaped anterior structure that is rimmed with a collar with parallel ridges that is distinctive within the gregarines. The new species is the second monocystid described from earthworms from Japan (the first was Monocystis perplexa Keller et Schall, 2020 - Keller and Schall 2020), and thus East Asia. The Japanese origin of the host earthworm A. tokioensis is indicated by the identity of the USA earthworms with those from Japan by sequencing the mitochondrial COI barcoding gene (Nouri-Aiin et al. 2021).

The parasite is so distinctive in morphology that it was clearly absent from all other earthworm species examined. All the other species, excepting Amynthas hilgendorfi, were infected with other monocystid parasites, and except for Monocystis perplexa in Amynthas agrestis, most likely not described taxa. Stomatocystis goerresi is distinctive from the type species in the genus by its larger size. Comparisons for Stomatocystis indica, based on Bandyopadhyay et al. (2006) vs. S. goerresi are given as $\mu \mathrm{m}$ for the largest measured for each stage to eliminate any bias in the cells measured or sample size. These are gamont (96 long vs. 598, and 59 for cell body vs. 354), funnel collar ridges (length 11 vs. 12), nucleus diameter (20 vs. 38), gametocyst diameter (102 vs. 458) with floating gametocyst of $S$. goerresi larger (232), and oocyst length (11 vs. 15). 

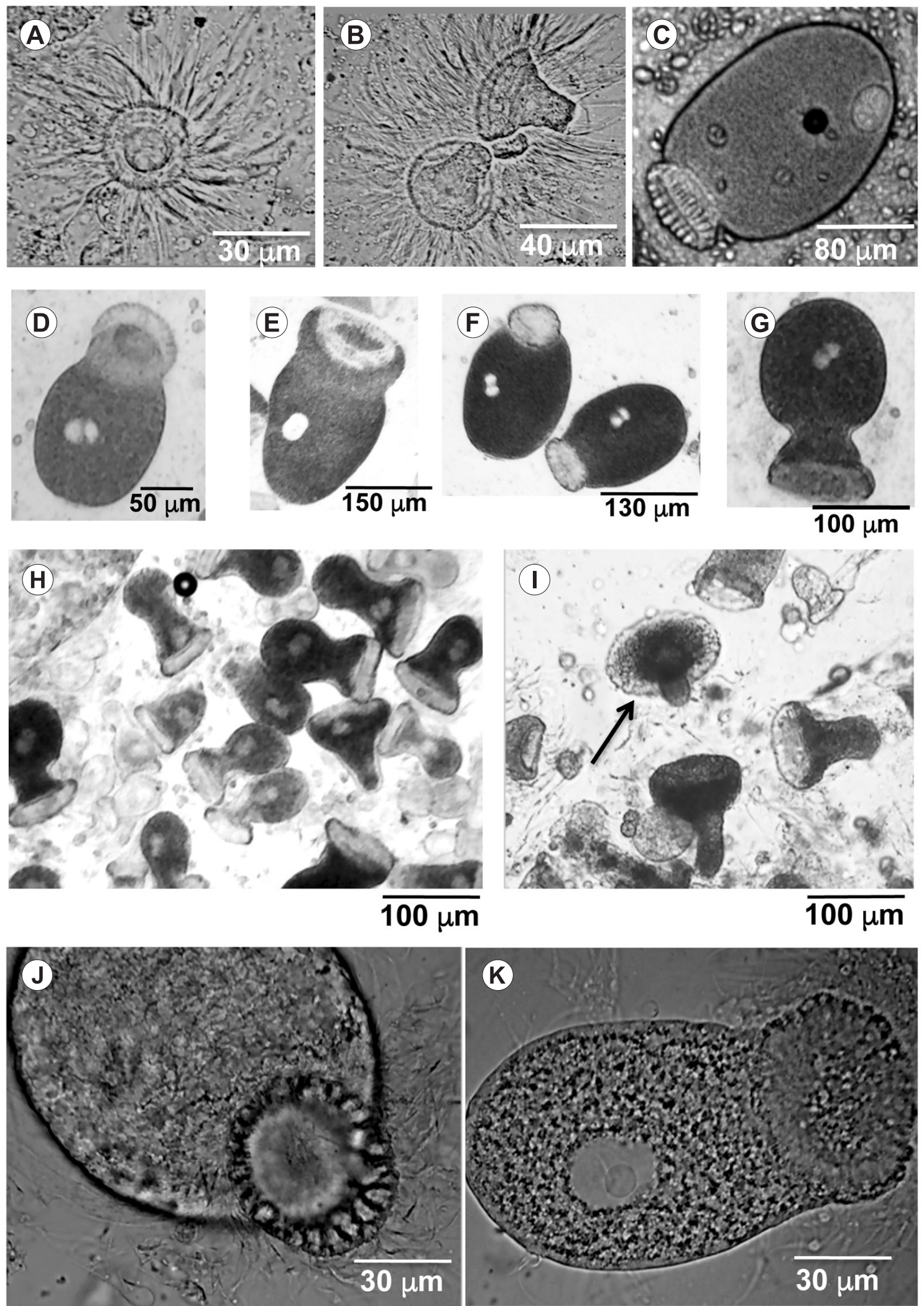

Fig. 1. Life stages of Stomatocystis goerresi sp. n. in the earthworm Amynthas tokioensis (Beddard). A - trophozoite showing early development of the funnel structure (centre of cell); B - small trophozoites showing early enlargement of funnel. Hair-like structures seen in these early stages are regarded here as the remnants of the earthworm's sperm morula, similar to what is seen in the feeding stages of species of Monocystis von Stein, 1848; $\mathbf{C}-\mathbf{G}$ - trophozoites/gamonts showing various forms of the funnel; note nucleus visible in each cell; $\mathbf{H}, \mathbf{I}$ - trophozoites/gamonts floating free in counting chamber showing diverse form and size of funnel. Arrow points to cell with funnel greatly expanded to form a fan. In some cells the funnel is larger than the cell body; $\mathbf{J}$ - close-up of funnel structure showing ridges around the perimeter; $\mathbf{K}$ - gamont showing the vesicular nucleus. Size bars are shown for each panel. 

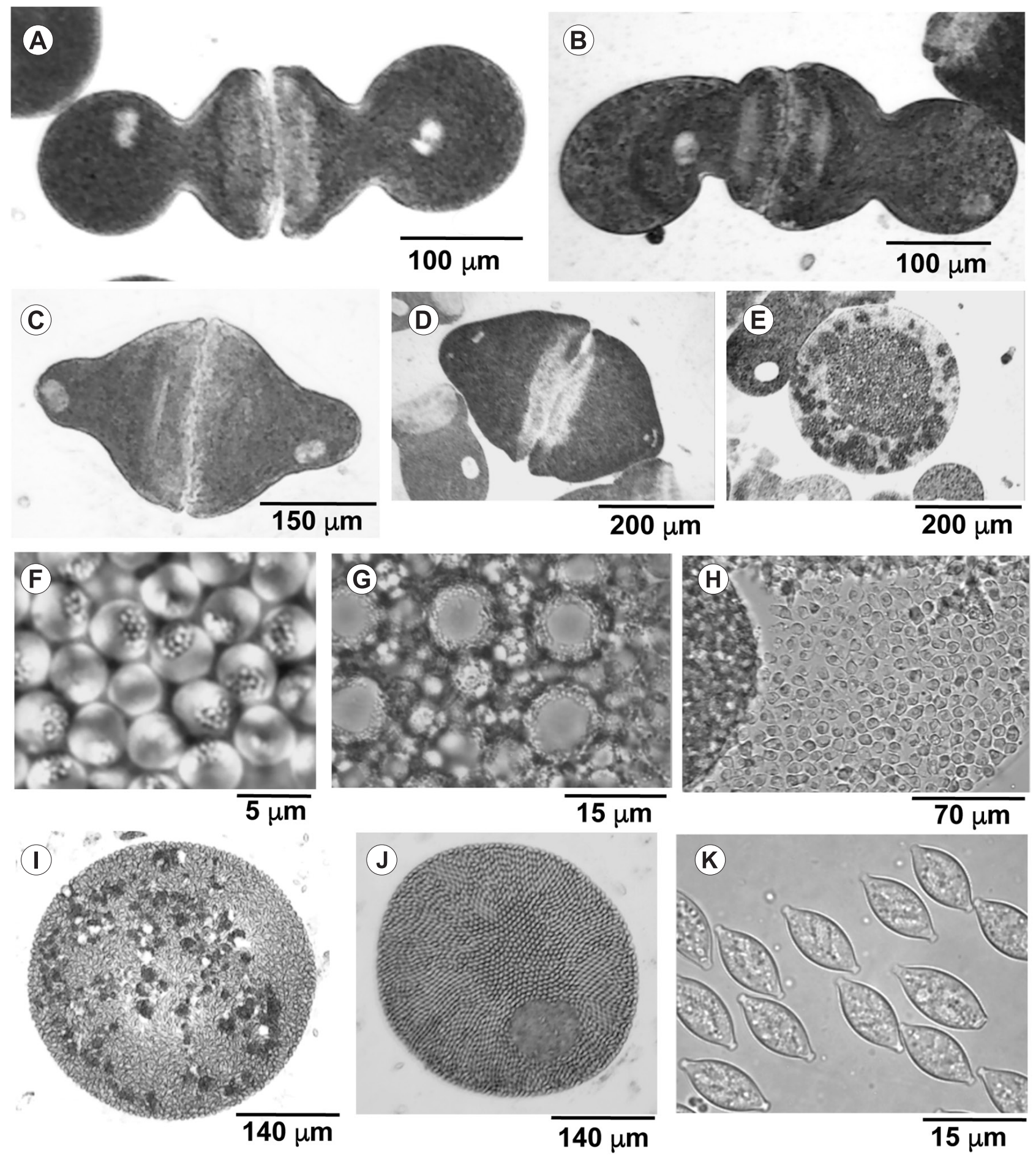

Fig. 2. Sexual reproduction in Stomatocystis goerresi sp. n. in the earthworm Amynthas tokioensis (Beddard). A - two gamonts in syzygy fuse by anterior funnel structure; $\mathbf{B}$ - complete fusion of two funnel structures; $\mathbf{C}$ - two gamonts in syzygy; funnel structures no longer obvious. D - two gamonts now in deltoid form during syzygy; $\mathbf{E}$ - early gametocyst with germinal centres scattered; $\mathbf{F}$ - gametes within the germinal centres; $\mathbf{G}$ - zygotes; $\mathbf{H}$ - dense cluster of zygotes within the gametocyst; $\mathbf{I}$ - immature gametocytes with developing oocysts. $\mathbf{J}$ - mature gametocysts full of $>1,000$ oocysts; $\mathbf{K}$ - mature oocysts. Size bars are shown for each panel.

Also, the geographic origin of the two earthworm species and parasites are south Asia vs. Japan and from different host species. The description for $S$. indica indicates the parasite was found outside the seminal vesicles, whereas $S$. goerresi was found only in that organ.

The most striking character of the parasite is the funnel. This structure is very variable in size relative to the cell body, so appears to stretch and change shape, sometimes forming a disk with the collar tight to the cell body, but other times greatly expanded to appear much larger than the cell body. Sometimes this expanded funnel is in the form of a broad disk or fan. The function of the funnel, therefore, invites speculation. The change in shape would alter the overall surface area, and thus the funnel may serve 
to move molecules and ions in and out of the cell. Floating cells in the Ringer's solution should all experience the same environment, yet quickly varied greatly in the form of the funnel. The funnels may also excrete substances that lead to the cell fusion when ready for the sexual cycle.

\section{DISCUSSION}

In erecting the genus Stomatocystis, Bandyopadhyay et al. (2006) placed the taxon into the Monocystidae, and subfamily Stomatophorinae. However, the diagnosis of the family Monocystidae is still not resolved. That is, does the family represent a true monophyletic clade? Levine (1988) characterised the Monocystidae as having gamonts that are spherical to cylindrical, gamonts solitary, with the anterior end lacking a mucron or other differentiation. However, he then described the Stomatophorinae as having a mucron transformed into a sucker. Note also that the 'mucron' for eugregarines is actually the epimerite (Simdyanov et al. 2017). Bandyopadhyay et al. (2006) refer to the complex structure at the anterior pole as both a mucron and epimerite. Other relevant characters are the orbital central vesicular nucleus and the distinctive fusiform oocysts with extended tips (Bandyopadhyay et al. 2006). Indeed, the oocyst form could be viewed as a clear synapomorphy (shared derived character) for the family. However, only one ultrastructure study has been presented for the monocystid oocyst, so the homology of the oocyst form is still uncertain (Crespi et al. 1981).

Monocystis von Stein, 1848, the type genus in the Monocystidae, was the first protist parasite to have a complex life cycle described (Henle 1845, von Stein 1848), and is often held as the exemplar for the family. However, the morphology of Stomatocystis is distinct from that of Monocystis, especially the anterior funnel structure, and the life cycle is also distinct from Monocystis. There is no morphological difference between the earliest small parasites which must be feeding stages (trophozoites) and the cells that undergo syzygy (gamonts). The sexual cycle begins with fusion of the funnels, thus anterior-anterior (Desportes and Schrével 2013), then the cells merge first as two deltoid forms, then into an orbicular gametocyst. In Monocystis the gamonts fuse laterally. Production of gametes in monocystids is typically around the periphery of the gamonts, but for Stomatocystis goerresi sp. n., the gametes are produced in several germinal centres. These are isogametes; thus there is sex without gender (see also Martinucci et al. 1981 for evidence of isogametes in another monocystid). The gametes are large, $5 \mu \mathrm{m}$ in diameter, with distinctive spotted caps that may serve for joining. The zygotes form, and then develop into the rhomboid oocysts. Oocyst production per gametocyst for gregarines can be large, such as for Blabericola migrator (Clopton, 1995), a parasite of cockroaches (> 120,000; Borengasser and Clopton 2019), but typically is much smaller for monocystids, such as the Monocystis species of $\sim 100$ oocysts (Keller and Schall 2020). Thus, oocyst production of $\sim 1,900$ is large for $S$. goerresi sp. n.

If the Monocystidae represent a true monophyletic clade, both the morphology of gamonts and life cycle would be highly variable among genera and species. In summary, the anterior end of the gamont may be undifferentiated (Monocystis) or produce a highly variable funnel structure (Stomatocystis). The gametes can be small and produced around the periphery of the mating gamonts (Monocystis) or much larger and produced in germinal centres scattered about the gametocyst. The gametes of Stomatocystis also display distinctive spotted tips. Syzygy in species of Monocystis begins with lateral fusion of the gamonts, but in Stomatocystis the anteriour funnels fuse. Thus, life cycles may not be phylogenetically informative for the family. Another conclusion is that the Monocystidae do not represent a monophyletic clade; this issue will only be resolved with molecular data for a substantial coverage of taxa within the nominate family.

Two aspects of the ecology of $S$. goerresi sp. n. are perplexing. First, the parasite was found at only one site. Allele frequency analysis for the earthworm shows the host has an origin at one site in Japan, but the worm populations consist of a set of clones (suggesting it is often parthenogenetic although nominally hermaphroditic) with no clone found at more than one site (Keller et al. 2017). This could indicate each site was seeded with a small number of worms during the horticultural trade, and the parasite traveled in only a few worms. Nonetheless, at the type location, most earthworms are infected, perhaps through eating the large number of oocysts cast into the soil by each infected host. Of the 21 earthworms found not to be infected, fully 17 were from a single sample day and likely from a patch within the study site, showing that if that patch had been missed that day, the overall prevalence would have been $98 \%$. The research site is only $<1$ ha, so the distribution of the new parasite may have a very small area.

Second, the parasite destroys the hermaphroditic earthworm's organ of sperm self-storage, thus castrating the male function. How does the earthworm population perpetuate? The presence of clones suggests it can reproduce via parthenogenesis, so the male-castrating parasite would limit, but not eliminate, the ability of the host to reproduce. The invasive earthworm's ability to colonise new sites must be affected by its reproductive mode and the damage done to its male function by the parasite.

Acknowledgements. I thank Josef Görres and Erin Keller for introducing me to the invasive Amynthas, and to the sites surveyed in the study. The type location is the site used by J. Görres for his long-term study of the Amynthas earthworms, and I thank him for his permission to dovetail with regular sampling of the earthworms. He and Maryam Nouri-Aiin provided many of the earthworms sampled for the study. 


\section{REFERENCES}

Adl S.M., Bass D., Lane C.E., Lukeš J., Schoch C.L., Smirnov A., Agatha S., Berney C., Brown M.W., Burki F., Cardenas P., Cepicka I., Chistyakova L., del Campo J., Dunthorn M., Edvardsen B., Eglit Y., Guillou L., Hampl V., Heiss A.A., Hoppenrath M., James T.Y., KarnKowsKa A., Karpov S., Kim E., Kolísko M., Kudryavtsev A., Lahr D.J.G., Lara E., Le Gall L., Lynn D.H., Mann D.G., Massana R., Mitchell E.A.D., Morrow C., Park J.S., Pawlowski J.W., Powell M.J., Richter D.J., Rueckert S., Shadwick L., Shimano S., Spiegel F.W., Torruella G., Youssef N., Zlatogursky V., Zhang Q. 2019: Revisions to the classification, nomenclature, and diversity of eukaryotes. J. Eukaryot. Microbiol. 66: 4-119.

Bandyopadhyay P.K., Mitra A.K., GöçMen B. 2006: A new endoparasitic gregarine genus, Stomatocystis indica gen. nov., sp. nov. (Apicomplexa: Sporozoea: Stomatoporinae) from the seminal vesicles of an Indian earthworm (Annelida: Oligochaeta) Amynthas diffringens Baird. Zootaxa 1191: 61-68.

Borengasser K., Clopton R.E. 2019: Gregarine oocyst production is a function of gametocyst size. J. Parasitol. 105: 454-458.

Braun M., LÜhe M. 1910: A Handbook of Practical Parasitology. John Bale and Son, London, 908 pp.

Cavalier-Smith T. 2014: Gregarine site-heterogeneous 18S rDNA trees, revision of gregarine higher classification, and the evolutionary diversification of Sporozoa. Eur. J. Protistol. 50: 472495.

Chang C.-H., Snyder B.A., Szlávecz K. 2016: Asian pheretimoid earthworms in North America north of Mexico: an illustrated key to the genera Amynthas, Metaphire, Pithemera, and Polypheretima (Clitellata: Megascolecidae). Zootaxa 4179: 495-529.

CLOPTON R.E. 2004: Standard nomenclature and metrics of plane shapes for use in gregarine taxonomy. Comp. Parasitol. 71: 130 140.

Clopton R.E. 2009: Phylogenetic relationships, evolution, and systematic revision of the septate gregarines (Apicomplexa: Eugregarinorida: Septatorina). Comp. Parasitol. 76: 167-190.

Crespi P., Martinucci G.B., Ferragosti E. 1981: Contributions to the study of monocystid gregarines parasites of Octolasium transpadanum. II. The fine organization of Apolocystis sp. oocyst. Boll. Zool. 48: 143-156.

Desportes I., Schrével J. 2013: The Gregarines: Early Branching Apicomplexa, Vol. 2. Koninklijke Brill NV, Leiden, 781 pp.

Henle J. 1845: Ueber die Gattung Gregarina. Arch. Anat. Physiol. Wiss. Med. 1845: 369-374.

Keller E., Görres J.H., Schall, J.J. 2017: Genetic structure of two invasive earthworms, Amynthas agrestis and Amynthas tokioensis (Oligochaeta, Megascolecidae), and a molecular method for species identification. Megadrilogica 22: 140-148.
Keller E.L., Schall J.J. 2020: A new species of Monocystis (Apicomplexa: Gregarina: Monocystidae) from the Asian invasive earthworm Amynthas agrestis (Megascolecidae), with an improved standard for Monocystis species descriptions. J. Parasitol. 106: 735-741.

Lentendu G., Mahe F., Bass D., Rueckert S., Stoeck T., Dunthorn M. 2018: Consistent patterns of high alpha and low beta diversity in tropical parasitic and free-living protists. Mol. Ecol. 27: 2846-2857.

LEVINE N.D. 1971: Uniform terminology for the protozoan phylum Apicomplexa. J. Protozool. 18: 352-355.

Levine N.D. 1988: The Protozoan Phylum Apicomplexa. Vol. I. CRC Press, Boca Raton, Florida, 154 pp.

Mahé F., de Vargas C., Gass D., Czeh L., Stamatakis A., Lara E., Singer D., Mayor J., Bunge J., Sernaker S., Siemensmeyer T., Trautmann I., Romac S., Berney C., Kozlov A., Mitchell E.A.D., Seppey C.V.M., Egge E., Lentendu G., Wirth R., Trueba G., Dunthorn M. 2017: Parasites dominate hyperdiverse soil protist communities in Neotropical rainforests. Nat. Ecol. Evol. 1: 0091.

Martinucci G.B., Crespi P., Ferragosti E. 1981: Contributions to the study of monocystid gregarines, parasites of Octolasium transpadanum. Ital. J. Zool. 48: 243-253.

Nouri-AiIn M., GörRes J.H. 2019: Earthworm cocoons: the cryptic side of invasive earthworm populations. Appl. Soil. Ecol. 141: $54-60$.

Nouri-Aitn M., Schall J.J., Keough C.A., Wen Y., Görres J.H. 2021: Identifying the unidentifiable: a PCR multiplex protocol for the diagnosis of invasive pheretimoid earthworm species, verified by morphological and barcode identification. Appl. Soil Ecol. 161: 103822.

REYNOLDS J.W. 2018: First earthworm (Annelida: Oligochaeta) species' collections in Canada and the continental United States. Megadrilogica 23: 1-50.

Rueckert S., Betts E.L., Tsaousis A.D. 2019: The symbiotic spectrum: where do the gregarines fit? Trends Parasitol. 35: 687-694.

Simdyanov T.G., Guillou L., Diakin A.Y., Mikhailov K.V., Schrével, J., Aleoshin V.V. 2017: A new view on the morphology and phylogeny of eugregarines suggested by the evidence from the gregarine Ancora sagittata (Leuckart, 1860) Labbé, 1899 (Apicomplexa: Eugregarinida). PeerJ 5: e3354.

von Stein F. 1848: Ueber die Nature der Gregarinen. Archiv Anat., Physiol. Wissenschaft. Med. 1848: 82-223.

Votý PKa J., Modrý D., Oborník M., Šlapeta J., Lukeš J. 2016: Apicomplexa. In: J.M. Archibald, A.G.B. Simpson, C.H. Slamovits, L. Margulis, M. Melkonian, D.J. Chapman, J.O. Corliss (Eds.), Handbook of the Protists. Springer, Cham, New York, pp. $1-58$.

Cite this article as: Schall J.J. 2021: Stomatocystis goerresi, a new species of gregarine parasite (Apicomplexa, Monocystidae) from the invasive Japanese earthworm Amynthas tokioensis (Megascolecidae), with a description of the parasite's life cycle. Folia Parasitol. 68: 022 . 